DR. JEAN SUVAN (Orcid ID : 0000-0002-6526-6235)

PROF. FRANCESCO D'AIUTO (Orcid ID : 0000-0001-8654-935X)

Article type : Original Article Clinical Periodontology

\title{
Obesity as Predictive Factor of \\ Periodontal Therapy Clinical Outcomes. \\ A Cohort Study
}

\author{
Suvan $\mathrm{J}^{1}$, Harrington $\mathrm{Z}^{3}$, Petrie $\mathrm{A}^{2}$, Patel $\mathrm{K}^{1}$, Darbar $\mathrm{U}^{1}$, \\ Donos $\mathrm{N}^{4^{*}}$, D'Aiuto $\mathrm{F}^{1^{*}}$
}

1 Unit of Periodontology, UCL Eastman Dental Institute, London, UK.

2 Unit of Biostatistics, UCL Eastman Dental Institute, London, UK.

3 King's College Dental Hospital and Institute, London UK.

4 Centre for Oral Clinical Research, Barts and The London School of Medicine and Dentistry, QMUL

*: equal contribution

Words count: 3474 words (excluding abstracts, acknowledgments, figure legends and references but including citations)

Figures and tables: 3

References: 36

Abstract: 296 words

\# Corresponding author:

Jean E. Suvan

Unit of Periodontology

This article has been accepted for publication and undergone full peer review but has not been through the copyediting, typesetting, pagination and proofreading process, which may lead to differences between this version and the Version of Record. Please cite this article as doi: 10.1111/JCPE.13261

This article is protected by copyright. All rights reserved 
UCL Eastman Dental Institute

Tel: +442034561086

j.suvan@ucl.ac.uk

Keywords: body mass index, obesity, periodontitis, periodontal therapy, prospective cohort

Conflict of interest and Sources of Funding:

The authors declare no conflicts of interest.

This article is protected by copyright. All rights reserved 


\section{ABSTRACT}

Aim: The study aim was to investigate the predictive role of obesity on clinical response following non-surgical periodontal therapy in individuals with severe periodontitis.

Methods: $57 \mathrm{BMI}$ obese and $58 \mathrm{BMI}$ normal non-smoker adults with periodontitis (defined as probing pocket depths (PPD) of $\geq 5 \mathrm{~mm}$ and alveolar bone loss of $>30 \%$ with $>50 \%$ of the teeth affected) received non-surgical periodontal therapy. Periodontal status was based upon PPD, clinical attachment level(CAL), and full mouth bleeding score(FMBS). Mean PPD, percentage sites PPD $>4 \mathrm{~mm}$, percentage sites PPD $>5 \mathrm{~mm}$, and FMBS at 2 and 6 months were outcome variables. Propensity score analysis was used to assess the effect of obesity on outcome variables after adjusting for confounders.

Results: Statistically significant higher clinical measures (mean PPD, mean percentage of sites with PPD $>4 \mathrm{~mm}$, mean percentage of sites with PPD $>5 \mathrm{~mm}$, and FMBS) were observed in the obese group than the normal group at baseline, 2 and 6 months after therapy $(p<0.01)$. At 2 and 6 months, obesity was associated with worse mean $\operatorname{PPD}(p<0.05)$, percentage sites with PPD $>4 \mathrm{~mm}(p<0.05)$, percentage sites with PPD $>5 \mathrm{~mm}(p<0.05)$, and FMBS $(p<0.01)$, independent of age, gender, ethnicity or plaque levels.

Conclusions: Obesity compared to normal BMI status was an independent predictor of poorer response following non-surgical periodontal therapy. 


\section{INTRODUCTION}

Obesity has been shown to modulate the host immune response resulting in increased susceptibility to infections (Falagas and Kompoti, 2006). It is well known that adipocytes (fat cells) are responsible for the production and release of pro-inflammatory mediators including cytokines (like IL-6), chemokines and can affect T-cell function (Falagas and Kompoti, 2006, Maury and Brichard, 2010, Ouchi et al., 2011). This can result in a state of low-grade systemic inflammation and altered insulin sensitivity therefore implicating this as the mechanism behind the association of obesity with chronic diseases such as, but not limited to, diabetes and cardiovascular disease (Huttunen and Syrjanen, 2013). As published in systematic reviews, obesity is associated with the prevalence, onset, progression and severity of periodontitis (Chaffee and Weston, 2010, Moura-Grec et al., 2014, Suvan et al., 2011).

Chronic periodontitis is a multi-factorial infectious/inflammatory disease of the gingival tissues of susceptible individuals in response to bacterial plaque accumulation. Pathogenesis is attributed to a dysbiotic state of the periodontal microbiota (Hajishengallis, 2015). Keystone pathogens such Porphyromonas gingivalis may upset the balance of microbial homeostasis resulting in an altered host-microbial interaction linked to particular inflammatory processes. Individual variability in host response mechanisms may result in variation in the degree of inflammation, both in terms of inflammatory response and resolution (Hajishengallis, 2015, Van Dyke and Kornman, 2008).

A pro-inflammatory systemic state propagated as a result of adipocytes release of inflammatory mediators in obesity has been shown to affect wound healing processes related to other diseases, although the mechanisms are not fully understood (Bagchi and Preuss, 2013, Wilson and Clark, 2003). Host immune and inflammatory responses are described as playing a pivotal role in wound healing in the body and suggested to be altered by many factors including obesity (Guo and Dipietro, 2010). A previously published observational analytical study using secondary analyses of pooled patient data revealed that obese individuals $\left(B M I \geq 30 \mathrm{~kg} / \mathrm{m}^{2}\right.$ ) had a poorer clinical response to periodontal therapy when compared to non-obese or overweight subjects. In particular, obese subjects had less favourable reductions in full mouth mean probing pocket depths and the percentage of sites presenting with probing pocket depth $>4 \mathrm{~mm}$ at 2 months following nonsurgical periodontal therapy when compared to non-obese individuals (Suvan et al., 2014). Results from prospective studies conducted to investigate the effect of obesity on periodontal therapy outcomes have provided variable results possibly due to small sample size, differing lengths of follow-up and the presence of confounding factors such as smoking as potential

This article is protected by copyright. All rights reserved 
sources of heterogeneity, therefore additional evidence from larger studies is merited (Akram et al., 2016, Gerber et al., 2016, Goncalves et al., 2015). The aim of this study was to ascertain if obesity is a predictor of the response to non-surgical periodontal therapy based upon clinical periodontal assessment measured at 2 months and 6 months following therapy in non-smoker $\mathrm{BMI}$ obese and BMI normal individuals suffering from moderate to severe periodontitis.

\section{MATERIALS AND METHODS}

\section{Study Design and Sample}

This was a single centre clinical cohort study with 6 months of follow-up and two parallel groups; WHO obese (BMI $\geq 30 \mathrm{~kg} / \mathrm{m}^{2}$ ) and WHO normal (BMI 18.5-24.99 kg/m²) individuals with moderate to severe chronic periodontitis. The study was approved by a UK national research ethics committee (NRES 09/H0806/43) prior to commencement and all study participants provided written consent. The study was registered via the International Standard Randomized Controlled Trial Number (ISRCTN14838813). Study reporting is in accordance with the STROBE statement for reporting of observational studies (Von Elm et al., 2007).

Sample size software nQuery Advisor 2009 was used to calculate the optimal sample size (Statsols, 2009). An appropriate sample was estimated to be 114 individuals (57 per group), assuming a 0.05 two-sided significance level and $90 \%$ power to detect, using a two-sample $t$-test, a difference between the two BMI groups of $0.3 \mathrm{~mm}$ in full mouth mean periodontal probing depth at six months after treatment (primary outcome). This was based on the assumption that the standard deviation of the response variable was between 0.47 resulting in an estimate of 54 participants per group (Suvan et al., 2014). A 5\% drop-out rate was included based upon dropout rates of previous studies conducted in the unit, resulting in the estimated 57 participants per group.

Study participants were recruited from individuals referred to the Unit of Periodontology, UCLH Eastman Dental Hospital between December 2009 and July 2012. All potential participants attending new patient clinics and meeting the inclusion criteria were offered participation in the study and provided with an information sheet to facilitate their decision. They were later contacted by telephone to confirm their interest to participate. Inclusion criteria comprised BMI obese and BMI normal individuals with elevated waist circumference according to the WHO categories (obesity=BMI $\geq 30 \mathrm{~kg} / \mathrm{m}^{2}$, normal=18.5-24.99 kg/m²), a minimum age of 35 years, never smoker or former smoker (stopped more 5 years prior to recruitment), and diagnosed with generalized 
moderate to severe periodontitis (probing pocket depths $>30 \%$ of sites with PPD $\geq 5 \mathrm{~mm}$ ) (D'Aiuto et al., 2004). WHO categories Underweight $\left(B M l<18.5 \mathrm{~kg} / \mathrm{m}^{2}\right)$ and Overweight $(B M \mid \geq 25-29.99$ $\mathrm{kg} / \mathrm{m}^{2}$ ) were excluded. All individuals were systemically healthy, not diagnosed with diabetes or pre-diabetes (self-report), not regularly taking non-steroidal anti-inflammatory drugs, had not taken antibiotics within 3 months of enrolment, and if female, were not pregnant or lactating. Participants had a minimum of 15 natural teeth present and had not received periodontal therapy within 12 months of the study baseline assessment.

All study participants received non-surgical periodontal therapy consisting of oral hygiene instructions, full mouth mechanical periodontal debridement (instrumentation to remove all soft and hard accretions from the tooth surface) in a single session (no time limit) using a combination of hand and ultrasonic instruments with local anaesthesia by a single clinician without time restriction (JS). Supra-gingival polishing was performed Day 1, Day 7, 1 month and 2 months following treatment. Oral hygiene guidance was provided at each of these visits. No sub-gingival debridement was performed between the full mouth treatment visit and the 6 month follow-up visit. Periodontal assessment was completed at baseline, 2 months following treatment and 6 months following treatment.

\section{Data Collection}

Demographic information, dental and medical history were obtained using a medical history interview. Body mass index was calculated as $\mathrm{kg} / \mathrm{m}^{2}$ based upon height and weight measured using a wall mounted height measure and electronic scales. Periodontal assessment consisting of full mouth probing pocket depths(PPD), recession(REC), bleeding on probing (FMBS), mobility and furcation involvement were recorded by a single calibrated examiner ( $\mathrm{ZH})$. Full mouth PPD and REC were performed using a University of North Carolina(UNC-15) periodontal probe at six sites per tooth. Clinical attachment level(CAL) was calculated from PPD and REC following data entry. Full mouth plaque scores (FMPS) were recorded as the percentages of total surfaces(6 aspects per tooth), which revealed the presence of plaque visual to the naked eye or appearing on the end of a periodontal probe when moved across the surface (O'Leary et al., 1972). Full mouth bleeding score was recorded based upon presence or absence of bleeding within 10-30 seconds following probing (Ainamo and Bay, 1975).

Before study commencement, 10 non-study patients with moderate to severe periodontitis participated in an examiner repeatability exercise to confirm intra-examiner repeatability. The 
examiner recorded PPD and REC twice on the same patient, with at least 30 minutes between measurements. The data were then analysed to confirm repeatability at a pre-determined success criteria level of agreement within $\pm 1 \mathrm{~mm}$ for PPD (primary outcome) in a minimum $98 \%$ of sites measured.

\section{Data Analysis}

Data were analysed using Stata Version 11 (StataCorp LP, 2009) and SPSS Version 23 (IBM Corporation, 2011) software. All study participants were included in the analysis. Last observation carried forward was employed to replace any missing data. After producing descriptive statistics and, for each study characteristic, comparing the two BMl groups using independent samples $t$-test for numerical data and chi-squared test for binary data, multivariable regression analysis with the outcome variable as periodontal status following therapy was performed to test the effect of obesity on the outcome of interest. Due to the non-randomised study design, resulting in differences in baseline characteristics between the BMI normal and BMI obese groups, a propensity score approach was used to overcome the potential effect of confounding (Austin, 2011). The propensity score was created for each individual using a logistic regression model in which the outcome variable was BMI normal/obese and the explanatory variables were those factors potentially associated with obesity that may also be associated with periodontal status following therapy (age, gender, ethnicity, full mouth plaque score, and the baseline value of the corresponding periodontal status measure). This propensity score was then included as a covariate in the multivariable linear regression model together with BMI group (normal/obese) in which mean PPD, CAL, percentage of sites with PPD>4mm, percentage of sites with PPD>5mm, and full mouth bleeding scores (FMBS) at 2 months and 6 months was each taken as a periodontal therapy outcome variable. A significance level of 0.05 was used for all hypothesis tests.

\section{RESULTS}

The examiner's assessment was shown to be repeatable within $\pm 1 \mathrm{~mm}$ for PPD in $98.9 \%$ of sites which was above the pre-defined target threshold of agreement. Good study visit adherence was achieved with 10 study visits being missed across all participants and study visits. The missed visits involved 8 participants ( 6 obese and 2 non-obese). In the obese group, 1 individual missed the day 1 , day 7 and 1 month healing and oral hygiene assessments visits due to flu. One additional person missed the 1 follow-up month visit, and 2 individuals missed the 2 month visits, all for personal reasons, but returned for the 6-month visit. At 6 months, 4 individuals did 
not return for the final assessment ( 2 obese, 2 non-obese) resulting in a total loss to follow-up of $4 \%$ of the total number recruited $(N=115)$ (Figure 1)

Figure 1 Study Flow Diagram

\section{Descriptive Results}

The study sample comprised 115 individuals (58 BMI normal, $57 \mathrm{BMI}$ obese) with age range 35 to 69 years. The BMI normal group was older, had a higher proportion of males and a higher proportion of white than other ethnic origin (age and ethnicity differences were statistically significant) (Table 1). Statistically, significantly higher average clinical measures of periodontitis (mean PPD, mean percentage of sites PPD $>4 \mathrm{~mm}$ ) were observed in the obese group than in the normal group at baseline, 2 and 6 months after therapy. Mean percentage of sites $>5 \mathrm{~mm}$ and FMBS scores were statistically significantly higher in obese individuals at 2 and 6 months after periodontal therapy. Differences in mean CAL and full mouth plaque scores were not statistically significant at either time points. Mean BMI in each group remained similar between baseline, 2 or 6 months.

\section{Table 2 Baseline, 2 and 6 Months Study Sample Characteristics}

\section{Obesity and Periodontal Status 2 and 6 Months Following Treatment}

Obesity had a statistically significant relationship with mean PPD $(p=0.03)$, percentage of sites with PPD $>4 \mathrm{~mm}(p=0.02)$, percentage of sites with $P P D>5 \mathrm{~mm}(p=0.03)$ and $\operatorname{FMBS}(p=0.009)$, independent of baseline values of each clinical variable, age, ethnicity or plaque at 2 months. A statistically significant relationship between obesity and mean PPD $(p=0.047)$, percentage of PPD $>4 \mathrm{~mm}(p=0.03)$, percentage of sites $>5 \mathrm{~mm}$, and FMBS $(p<0.001)$ existed at 6 months with difference magnitude increasing from 2 to 6 months for percentage of sites $>5 \mathrm{~mm}$ and FMBS (Table 2).

Mean PPD in obese patients was $0.14 \mathrm{~mm}$ greater than BMI normal patients at 2 and 6 months. Obesity was an independent predictor of poorer periodontal treatment outcome at 2 months $(p=0.020)$ such that obese individuals had, on average, $2.7 \%(95 \% \mathrm{Cl} 0.4 \%-4.9 \%)$ more sites with PPD $>4 \mathrm{~mm}$ than those with a BMI within the normal range. This difference remained at 6 months 
$(p=0.03)$, with those obese individuals having on average $2.8 \%(95 \% \mathrm{Cl} 0.3 \%-5.3 \%)$ more sites with PPD $>4 \mathrm{~mm}$ than those with normal weight. Obese patients also had, on average, $1.5 \%$ (95\% $\mathrm{Cl} 0.2 \%-2.9 \%)$ and $2 \%(95 \% \mathrm{Cl} 0.5 \%-3.5 \%)$ more sites with PPD>5mm at 2 and 6 months, respectively. The full mouth bleeding score in individuals with obesity was $4.3 \%(95 \% \mathrm{Cl} 1.1 \%$ $7.5 \%)$ and $7.1 \%(95 \% \mathrm{Cl} 4.1 \%-10.1 \%)$ at 2 and 6 months, respectively, following treatment. $\mathrm{CAL}$ did not demonstrate a statistically significant difference between groups at either time point (Table 2).

\section{Table 2 Propensity Score Analysis Results (BMI Obese vs BMI Normal)}

\section{Discussion}

This prospective cohort study provides evidence that obesity is a predictor of clinical periodontal parameters following non-surgical periodontal therapy. Study results confirmed an association of obesity with mean PPD, percentage of sites with PPD $>4 \mathrm{~mm}$, percentage of sites with PPD $>5 \mathrm{~mm}$, and mean FMBS at 2 and 6 months post therapy. These associations were independent of differences in age, gender, ethnicity, and plaque levels amongst study participants using a propensity score analysis that takes into account differences at baseline.

Previously published research has suggested a positive association between obesity and prevalence, progression, and severity of periodontitis (Chaffee and Weston, 2010, Moura-Grec et al., 2014, Suvan et al., 2011). Some reports of the association between obesity and disease presentation at 2 and 6 months following periodontal therapy have been published in smaller population samples with inconsistent results (Altay et al., 2013, Lakkis et al., 2012, Zuza et al., 2011). The results of this study contribute to the body of evidence investigating the effect of obesity on treatment outcomes and are based upon a sample size calculated a priori according to previous findings with comprehensive assessment of clinical response including mean PPD, pocket closure, bleeding on probing all measured at 2 and 6 months.

The relationship between obesity and treatment outcomes may be influenced by a number of factors, as reported in previously published cross-sectional studies of periodontal status, including the known influence of plaque levels on full mouth bleeding on probing scores. Smoking is a risk factor for periodontitis affecting the treatment response to periodontal therapy and has been reported to contribute to systemic inflammation, possibly in a synergistic way with obesity (Bagchi and Preuss, 2013, Bostrom et al., 1999). This study did not include smokers, therefore 
removing the possibility of a confounding effect of smoking. Other known risk factors for periodontitis, namely age, gender, ethnicity and plaque, were included in the analysis to control for confounding. A similar relationship between obesity and the clinical periodontal status was observed at both 2 and 6 months after adjusting for these possible confounders.

Full mouth bleeding score has been stated to be vital in confirming the effects of a risk factor on disease manifestation and response to therapy (Tonetti et al., 2005). In this study, obesity was a statistically significant predictor of full mouth bleeding score at 2 and 6 months post-treatment. In addition, the mean percentage of sites with PPD $>4 \mathrm{~mm}$ or PPD $>5 \mathrm{~mm}$ post treatment were higher in obese individuals, therefore suggesting increased future treatment needs in terms of possible surgical treatment, increased frequency of supportive periodontal therapy appointments or potential for further periodontal disease progression (Matuliene et al., 2008).

In a recent prospective analysis of 172 individuals over 10 years it was reported that, although full mouth bleeding scores were not predictive of future tooth loss, presence/absence of BOP was associated with doubled odds of tooth loss. Similarly, persistence of periodontal pockets with PPD $>5 \mathrm{~mm}$ and $>6 \mathrm{~mm}$ were among the strong predictors of future loss of teeth (ORs greater than 5) (Matuliene et al., 2008). The results from this study support the notion that obese individuals, following a course of non-surgical periodontal therapy, would present a greater risk of future progression of periodontitis and possibly tooth loss than those individuals with normal BMI.

Based on current evidence three main consequences of obesity have been advocated, all of which may play a role in wound healing; the stimulation of a pro-inflammatory systemic state, an altered insulin sensitivity and a modification of the local/gingival pathogenic flora towards a more resistant/virulent biofilm (Hotamisligil, 2006, Ouchi et al., 2011, Maciel et al., 2016, Zeigler et al., 2012). The hypothesis of a hyper-inflammatory systemic response triggered by obesity is shared among other co-morbidities. Adipose tissue has been shown to alter macrophage, $T$ and $B$ cell functions (Maury and Brichard, 2010). All of these functions and cellular players have been identified as involved during the onset and progression of chronic periodontitis. An increase in reactive oxygen species has been shown to be associated with increased levels of adipocytokines secreted by adipose tissue. Evidence suggests that oxidative stress plays a crucial role in the association between periodontitis and systemic diseases (Chapple and Matthews, 2007). 
Further to this, variations in immune response could also result from the altered insulin sensitivity attributed to adipocyte function (Maury and Brichard, 2010). Like diabetes, abnormalities in the immune response may result in compromised healing associated with altered insulin sensitivity. Defence cells such as macrophages and polymorphonuclear leucocytes (PMNs) function less effectively in obese than in normal weight individuals. There are also deficiencies in chemokinesis, adherence and phagocytosis in presence of obesity, therefore the body's response to bacterial insult is less effective (Maury and Brichard, 2010, Ouchi et al., 2011). Alternatively, these results could be due to an exaggerated local inflammatory response to dental plaque accumulations at the tooth site level. Indeed higher levels of TNF- $\alpha$ have been demonstrated in the gingival crevice of obese individuals when compared to normal weight individuals (Lundin et al., 2004).

In addition to exaggerated local responses, differences in the plaque biofilm quality and quantity have been suggested. Haffajee and Socransky reported an overgrowth of $T$. forsythia in subgingival biofilms of overweight and obese individuals (Haffajee and Socransky, 2009). There is still much to learn about qualitative and quantitative aspects of bacterial plaque biofilm in obese versus non-obese. Recently published papers investigating differences in microbiota of obese and non-obese suggest differences (Maciel et al., 2016, Silva-Boghossian et al., 2018). It has been proposed that a diet high in carbohydrates promotes a proinflammatory microbiota (Spreadbury, 2012).

It is interesting to note that mean plaque levels did not differ significantly between groups at baseline, 2 or 6 months. It has been suggested that meticulous plaque control for individuals with obesity may be an extra challenge due to access issues related to the limitations in achieving appropriate toothbrush or interdental brush placement due to excess fat of the forearms, fingers, cheeks or tongue (Suvan and D'Aiuto, 2013, Brennick et al., 2014). Mean FMPS in both groups at 2 and 6 months were slightly higher than target standards to facilitate healing following nonsurgical therapy. This is possibly due to the delivery of therapy in one visit with minimal oral hygiene reinforcement until 2 months not providing optimal opportunities to facilitate patient plaque control. Plaque control level attained may have been a confounder of the observed association although plaque was not statistically significant when included in the multivariable models. 
Limitations to the interpretation of these results include the cohort study design selecting study participants according to presence of the exposure (obesity) resulting in the inability to blind the examiner to the exposure of interest. It is acknowledged that randomised trials are superior design for investigating differences in treatment response between groups. However, randomised controlled trials of exposures such as smoking or obesity are complex and justified as later stage trials.

Reliance on patients' self-reported presence or absence of diabetes during recruitment is another limitation. Blood glucose levels were not recorded before periodontal treatment, therefore some pre-diabetic or undiagnosed diabetics may have entered the study. Efforts were made during the medical history interview to confirm any warnings of possible pre-diabetes. It is recognised that insulin resistance could be a confounding factor in the demonstrated association, but altered insulin sensitivity is one of the known effects of obesity and possible mechanisms of the investigated association (Genco et al., 2005).

A strength of this study was minimisation of confounding factors through the exclusion of smokers and diabetics from the study sample, factors similarly reported in some previously published evidence (Lakkis et al., 2012, Gerber et al., 2016, Nascimento et al., 2016). Further strengths included the 6 month follow-up with no change in BMI status, which is longer than some previous studies (Eldin AM, 2013, Duzagac et al., 2016, Al-Zahrani and Alghamdi, 2012). Sample size calculation resulted in a sample much larger than previously published research (Bouaziz et al., 2015, Duzagac et al., 2016, Goncalves et al., 2015, Lakkis et al., 2012). Low loss to follow-up reducing the risk of attrition was also an attribute of this study.

The study results suggest that it is important for dental practitioners to consider obesity as part of clinical practice assessment to identify individuals at risk of poorer response to periodontal therapy. Obesity is a complex disease with many implications for patient management, inferring it is critical for dental professionals to continue to increase their understanding and awareness of obesity and management of oral health in the obese patients (Suvan and D'Aiuto, 2013).

\section{Overall Conclusions}

Obesity compared to BMI normal status was independently predictive of a worse response to periodontal therapy assessed by periodontal status at 2 and 6 months. In this non-smoker severe chronic periodontitis sample, this effect was independent of plaque and age differences. 


\section{Clinical relevance}

Scientific rationale for the study: Epidemiological studies and some intervention studies suggest periodontitis to be associated with overweight and obesity. Current evidence of the effect of obesity on periodontal therapy outcomes is inconclusive so further research is merited.

Principal findings: BMI category obese $\left(\geq 30 \mathrm{~kg} / \mathrm{m}^{2}\right)$ was associated with higher levels of bleeding upon probing and higher number of residual sites $>4 \mathrm{~mm}$ at 6 months following non-surgical periodontal therapy compared to those of BMI category normal $\left(18.5-24.99 \mathrm{~kg} / \mathrm{m}^{2}\right)$. Practical implications: People with a body mass index higher than $30 \mathrm{~kg} / \mathrm{m}^{2}$ may respond less well to non-surgical periodontal therapy.

\section{ACKNOWLEDGEMENTS}

This work was undertaken at UCLH/UCL, which received a proportion of funding from the Department of Health's NIHR Biomedical Research Centers funding scheme. The study was partially funded by the UCL Eastman Dental Institute Unit of Periodontology.

\section{FIGURE and TABLE LEGEND}

\section{Figure 3 Study Flow Diagram}

Table 4 Baseline, 2 and 6 Months Study Sample Characteristics

Table 2 Propensity Score Analysis Results (BMI Obese vs BMI Normal) 


\section{REFERENCES}

AINAMO, J. \& BAY, I. 1975. Problems and proposals for recording gingivitis and plaque. Int Dent $J, 25,229-35$.

AKRAM, Z., SAFII, S. H., VAITHILINGAM, R. D., BAHARUDDIN, N. A., JAVED, F. \& VOHRA, F. 2016. Efficacy of non-surgical periodontal therapy in the management of chronic periodontitis among obese and non-obese patients: a systematic review and metaanalysis. Clin. Oral Investig, 20, 903-914.

AL-ZAHRANI, M. S. \& ALGHAMDI, H. S. 2012. Effect of periodontal treatment on serum Creactive protein level in obese and normal-weight women affected with chronic periodontitis. Saudi Med J, 33, 309-14.

ALTAY, U., GURGAN, C. A. \& AGBAHT, K. 2013. Changes in inflammatory and metabolic parameters after periodontal treatment in patients with and without obesity. J. Periodontol, 84, 13-23.

AUSTIN, P. C. 2011. An Introduction to Propensity Score Methods for Reducing the Effects of Confounding in Observational Studies. Multivariate Behav Res, 46, 399-424.

BAGCHI, D. \& PREUSS, H. G. 2013. Obesity : epidemiology, pathophysiology, and prevention, Boca Raton, FL, CRC Press.

BOSTROM, L., LINDER, L. E. \& BERGSTROM, J. 1999. Smoking and crevicular fluid levels of IL-6 and TNF-alpha in periodontal disease. J Clin Periodontol, 26, 352-7.

BOUAZIZ, W., DAVIDEAU, J. L., TENENBAUM, H. \& HUCK, O. 2015. Adiposity Measurements and Non-Surgical Periodontal Therapy Outcomes. J Periodontol, 86, 1030-7.

BRENNICK, M. J., DELIKATNY, J., PACK, A. I., PICKUP, S., SHINDE, S., ZHU, J. X., ROSCOE, I., KIM, D. Y., BUXBAUM, L. U., CATER, J. R. \& SCHWAB, R. J. 2014. Tongue fat infiltration in obese versus lean Zucker rats. Sleep, 37, 1095-102, 1102A-1102C. 
CHAFFEE, B. W. \& WESTON, S. J. 2010. Association between chronic periodontal disease and obesity: a systematic review and meta-analysis. J. Periodontol, 81, 1708-1724.

CHAPPLE, I. L. \& MATTHEWS, J. B. 2007. The role of reactive oxygen and antioxidant species in periodontal tissue destruction. Periodontol 2000, 43, 160-232.

D'AIUTO, F., PARKAR, M., ANDREOU, G., SUVAN, J., BRETT, P. M., READY, D. \& TONETTI, M. S. 2004. Periodontitis and systemic inflammation: control of the local infection is associated with a reduction in serum inflammatory markers. J Dent Res, 83, 156-60.

DUZAGAC, E., CIFCIBASI, E., ERDEM, M. G., KARABEY, V., KASALI, K., BADUR, S. \& CINTAN, S. 2016. Is obesity associated with healing after non-surgical periodontal therapy? A local vs. systemic evaluation. J Periodontal Res, 51, 604-12.

ELDIN AM, N. S., HASSAN NE 2013. Effect of Non-surgical Periodontal Therapy on Interleukin-8 (il-8) Level in gingival Crevicular Fluid in Overweight and Obese Subjects with Chronic Periodontitis. World Journal of Medical Sciences 9, 173-179.

FALAGAS, M. E. \& KOMPOTI, M. 2006. Obesity and infection. Lancet Infect. Dis, 6, 438-446.

GENCO, R. J., GROSSI, S. G., HO, A., NISHIMURA, F. \& MURAYAMA, Y. 2005. A proposed model linking inflammation to obesity, diabetes, and periodontal infections. Journal of Periodontology. 76(11 Suppl):2075-84,.

GERBER, F. A., SAHRMANN, P., SCHMIDLIN, O. A., HEUMANN, C., BEER, J. H. \& SCHMIDLIN, P. R. 2016. Influence of obesity on the outcome of non-surgical periodontal therapy - a systematic review. BMC. Oral Health, 16, 90.

GONCALVES, T. E., FERES, M., ZIMMERMANN, G. S., FAVERI, M., FIGUEIREDO, L. C., BRAGA, P. G. \& DUARTE, P. M. 2015. Effects of scaling and root planing on clinical response and serum levels of adipocytokines in patients with obesity and chronic periodontitis. J Periodontol, 86, 53-61.

GUO, S. \& DIPIETRO, L. A. 2010. Factors affecting wound healing. J Dent Res, 89, 219-29. 
HAFFAJEE, A. D. \& SOCRANSKY, S. S. 2009. Relation of body mass index, periodontitis and Tannerella forsythia. J Clin Periodontol, 36, 89-99.

HAJISHENGALLIS, G. 2015. Periodontitis: from microbial immune subversion to systemic inflammation. Nat. Rev. Immunol, 15, 30-44.

HOTAMISLIGIL, G. S. 2006. Inflammation and metabolic disorders. Nature, 444, 860-867.

HUTTUNEN, R. \& SYRJANEN, J. 2013. Obesity and the risk and outcome of infection. Int. J. Obes. (Lond), 37, 333-340.

IBM CORPORATION 2011. SPSS Statistics for Windows. 23.0 ed. Armonk, NY: IBM Corporation.

LAKKIS, D., BISSADA, N. F., SABER, A., KHAITAN, L., PALOMO, L., NARENDRAN, S. \& ALZAHRANI, M. S. 2012. Response to periodontal therapy in patients who had weight loss after bariatric surgery and obese counterparts: a pilot study. J Periodontol, 83, 684-9.

LUNDIN, M., YUCEL-LINDBERG, T., DAHLLOF, G., MARCUS, C. \& MODEER, T. 2004. Correlation between TNFalpha in gingival crevicular fluid and body mass index in obese subjects. Acta Odontol. Scand, 62, 273-277.

MACIEL, S. S., FERES, M., GONCALVES, T. E., ZIMMERMANN, G. S., DA SILVA, H. D., FIGUEIREDO, L. C. \& DUARTE, P. M. 2016. Does obesity influence the subgingival microbiota composition in periodontal health and disease? J Clin. Periodontol, 43, 10031012.

MATUliENE, G., PJETURSSON, B. E., SALVI, G. E., SCHMIDLIN, K., BRAGGER, U., ZWAHLEN, M. \& LANG, N. P. 2008. Influence of residual pockets on progression of periodontitis and tooth loss: results after 11 years of maintenance. J Clin Periodontol, 35, 685-95.

MAURY, E. \& BRICHARD, S. M. 2010. Adipokine dysregulation, adipose tissue inflammation and metabolic syndrome. Mol. Cell Endocrinol, 314, 1-16. 
MOURA-GREC, P. G., MARSICANO, J. A., CARVALHO, C. A. \& SALES-PERES, S. H. 2014. Obesity and periodontitis: systematic review and meta-analysis. Cien. Saude Colet, 19, 1763-1772.

NASCIMENTO, G. G., LEITE, F. R., CORREA, M. B., PERES, M. A. \& DEMARCO, F. F. 2016. Does periodontal treatment have an effect on clinical and immunological parameters of periodontal disease in obese subjects? A systematic review and meta-analysis. Clin Oral Investig, 20, 639-47.

O'LEARY, T. J., DRAKE, R. B. \& NAYLOR, J. E. 1972. The plaque control record. J Periodontol, $43,38$.

OUCHI, N., PARKER, J. L., LUGUS, J. J. \& WALSH, K. 2011. Adipokines in inflammation and metabolic disease. Nat. Rev. Immunol, 11, 85-97.

SILVA-BOGHOSSIAN, C. M., CESARIO, P. C., LEAO, A. T. T. \& COLOMBO, A. P. V. 2018. Subgingival microbial profile of obese women with periodontal disease. J Periodontol, 89, 186-194.

SPREADBURY, I. 2012. Comparison with ancestral diets suggests dense acellular carbohydrates promote an inflammatory microbiota, and may be the primary dietary cause of leptin resistance and obesity. Diabetes Metab Syndr Obes, 5, 175-89.

STATACORP LP 2009. Stata statistical software, version 11. College Station.

STATSOLS. 2009. nQuery Sample Size Resource Center [Online]. Available: https://www.statsols.com/sample-size-resources [Accessed Last accessed 2019].

SUVAN, J., D'AIUTO, F., MOLES, D. R., PETRIE, A. \& DONOS, N. 2011. Association between overweight/obesity and periodontitis in adults. A systematic review. Obes. Rev, 12, e381e404.

SUVAN, J. \& D'AIUTO, F. 2013. Assessment and management of oral health in obesity. Current Obesity Reports, 2, 142-149. 
SUVAN, J., PETRIE, A., MOLES, D. R., NIBALI, L., PATEL, K., DARBAR, U., DONOS, N., TONETTI, M. \& D'AIUTO, F. 2014. Body mass index as a predictive factor of periodontal therapy outcomes. J Dent Res, 93, 49-54.

TONETTI, M. S., CLAFFEY, N. \& EUROPEAN WORKSHOP IN PERIODONTOLOGY GROUP, C. 2005. Advances in the progression of periodontitis and proposal of definitions of a periodontitis case and disease progression for use in risk factor research. Group C consensus report of the 5th European Workshop in Periodontology. J Clin Periodontol, 32 Suppl 6, 210-3.

VAN DYKE, T. E. \& KORNMAN, K. S. 2008. Inflammation and factors that may regulate inflammatory response. J Periodontol, 79, 1503-1507.

VON ElM, E., ALTMAN, D. G., EGGER, M., POCOCK, S. J., GØTZSCHE, P. C., VANDENBROUCKE, J. P. \& MEDICINE, S. I. J. P. 2007. The Strengthening the Reporting of Observational Studies in Epidemiology (STROBE) statement: guidelines for reporting observational studies. 4 , e296.

WILSON, J. A. \& CLARK, J. J. 2003. Obesity: impediment to wound healing. Crit Care Nurs Q, $26,119-32$.

ZEIGLER, C. C., PERSSON, G. R., WONDIMU, B., MARCUS, C., SOBKO, T. \& MODEER, T. 2012. Microbiota in the oral subgingival biofilm is associated with obesity in adolescence. Obesity (Silver Spring), 20, 157-64.

ZUZA, E. P., BARROSO, E. M., CARRARETO, A. L., PIRES, J. R., CARLOS, I. Z., THEOdORO, L. H. \& TOLEDO, B. E. 2011. The role of obesity as a modifying factor in patients undergoing non-surgical periodontal therapy. J. Periodontol, 82, 676-682. 
Table 1 Baseline, 2 and 6 Months Study Sample Characteristics

\begin{tabular}{|c|c|c|c|c|c|c|c|c|c|}
\hline Variable, mean(SD) & $\begin{array}{c}\text { BMI Normal } \\
\text { Baseline } \\
n=58\end{array}$ & $\begin{array}{c}\text { BMI Obese } \\
\text { Baseline } \\
n=57\end{array}$ & p-value & $\begin{array}{c}\text { BMI Normal } \\
2 \text { Month } \\
n=58\end{array}$ & $\begin{array}{c}\text { BMI Obese } \\
2 \text { Month } \\
n=57\end{array}$ & p-value & $\begin{array}{c}\text { BMI Normal } \\
6 \text { Month } \\
n=58\end{array}$ & $\begin{array}{c}\text { BMI Obese } \\
6 \text { Month } \\
n=57\end{array}$ & p-value \\
\hline Age, years & 49.53 (7.99) & $46.61(6.76)^{\star}$ & $\mathrm{p}=0.037$ & & & & & & \\
\hline Gender: Male n(\%) & $29(50)$ & $23(40.4)$ & $\mathrm{p}=0.351$ & & & & & & \\
\hline Ethnicity: White $\mathrm{n}(\%)$ & $41(70.7)$ & $29(50.9)^{*}$ & $\mathrm{p}=0.036$ & & & & & & \\
\hline $\mathrm{BMI}\left(\mathrm{kg} / \mathrm{m}^{2}\right)$ & $23.10(1.33)$ & $35.58(5.41)^{\star}$ & $p<0.001$ & $23.07(1.41)$ & $35.53(5.37)^{\star}$ & $p<0.001$ & $23.14(1.57)$ & $35.53(5.56)^{*}$ & $p<0.001$ \\
\hline WC (cm) & $84.93(7.68)$ & $110.70(10.99)^{*}$ & $p<0.001$ & $85.71(7.35)$ & $110.43(11.49)^{*}$ & $p<0.001$ & $86.05(7.93)$ & $111.95(11.91)^{*}$ & $p<0.001$ \\
\hline \# Teeth & $28.10(2.70)$ & $27.56(3.13)$ & $p=0.323$ & $27.86(2.85)$ & $26.84(3.93)$ & $p=0.114$ & $27.81(2.86)$ & $26.84(3.93)$ & $p=0.134$ \\
\hline $\operatorname{PPD}(\mathrm{mm})$ & $3.37(0.62)$ & $3.69(0.72)^{*}$ & $p=0.012$ & $2.55(0.45)$ & $2.85(0.50)^{\star}$ & $p=0.001$ & $2.55(0.41)$ & $2.86(0.55)^{*}$ & $p=0.001$ \\
\hline $\mathrm{CAL}(\mathrm{mm})$ & $3.91(0.86)$ & $4.16(0.99)$ & $\mathrm{p}=0.161$ & $3.26(0.87)$ & $3.50(0.87)$ & $p=0.155$ & $3.26(0.85)$ & $3.46(0.88)$ & $p=0.220$ \\
\hline$\%$ of $\mathrm{PPD}>4 \mathrm{~mm}$ & $26.68(13.70)$ & $32.01(14.77)^{\star}$ & $\mathrm{p}=0.047$ & $9.81(7.42)$ & $14.38(9.33)^{*}$ & $p=0.004$ & $9.06(6.75)$ & $14.53(10.09)^{*}$ & $p=0.001$ \\
\hline$\%$ of $\mathrm{PPD}>5 \mathrm{~mm}$ & $13.79(10.43)$ & $17.87(13.04)$ & $p=0.067$ & $3.91(3.56)$ & $6.67(6.51)^{*}$ & $p=0.006$ & $3.31(3.65)$ & $6.92(6.75)^{*}$ & $\mathrm{p}=0.001$ \\
\hline FMBS $\%$ & $47.34(20.10)$ & $52.61(19.47)$ & $\mathrm{p}=0.156$ & $21.19(9.65)$ & $27.39(10.66)^{\star}$ & $p=0.001$ & $21.73(10.14)$ & $31.21(11.82)^{*}$ & $p<0.001$ \\
\hline FMPS \%: & $61.52(19.04)$ & $64.14(17.89)$ & $\mathrm{p}=0.450$ & $25.80(16.09)$ & $30.59(17.96)$ & $\mathrm{p}=0.135$ & $29.62(18.20)$ & 32.67 (20.86) & $\mathrm{p}=0.404$ \\
\hline
\end{tabular}

Entries for normal and obese groups are mean (SD) apart from gender and ethnicity, BMI Normal $=18.5-24.99 \mathrm{~kg} / \mathrm{m}^{2}$, BMI Obese $=\geq 30 \mathrm{~kg} / \mathrm{m}^{2}$

This article is protected by copyright. All rights reserved 
Table 2 Propensity Score Analysis Results (BMI Obese vs BMI Normal)

\begin{tabular}{|c|c|c|c|c|}
\hline Periodontal & 2 Months & & 6 Months & \\
\hline Status & Coefficient $(95 \% \mathrm{Cl})$ & $p$ value & Coefficient $(95 \% \mathrm{Cl})$ & $p$ value \\
\hline PPD mean (mm) & $0.14(0.16,0.27)$ & 0.028 & $0.14(0.01,0.28)$ & 0.047 \\
\hline$\%$ PPD $>4 \mathrm{~mm}$ & $2.69(0.43,4.95)$ & 0.020 & $2.82(0.34,5.30)$ & 0.026 \\
\hline$\%$ PPD $>5 \mathrm{~mm}$ & $1.53(0.15,2.90)$ & 0.029 & $2.02(0.53,3.50)$ & 0.008 \\
\hline FMBS (\%) & $4.32(1.07,7.58)$ & 0.009 & $7.09(4.08,10.11)$ & $<0.001$ \\
\hline CAL mean (mm) & $0.06(-0.09,0.22)$ & 0.409 & $0.02(-0.16,0.20)$ & 0.827 \\
\hline
\end{tabular}

This article is protected by copyright. All rights reserved 


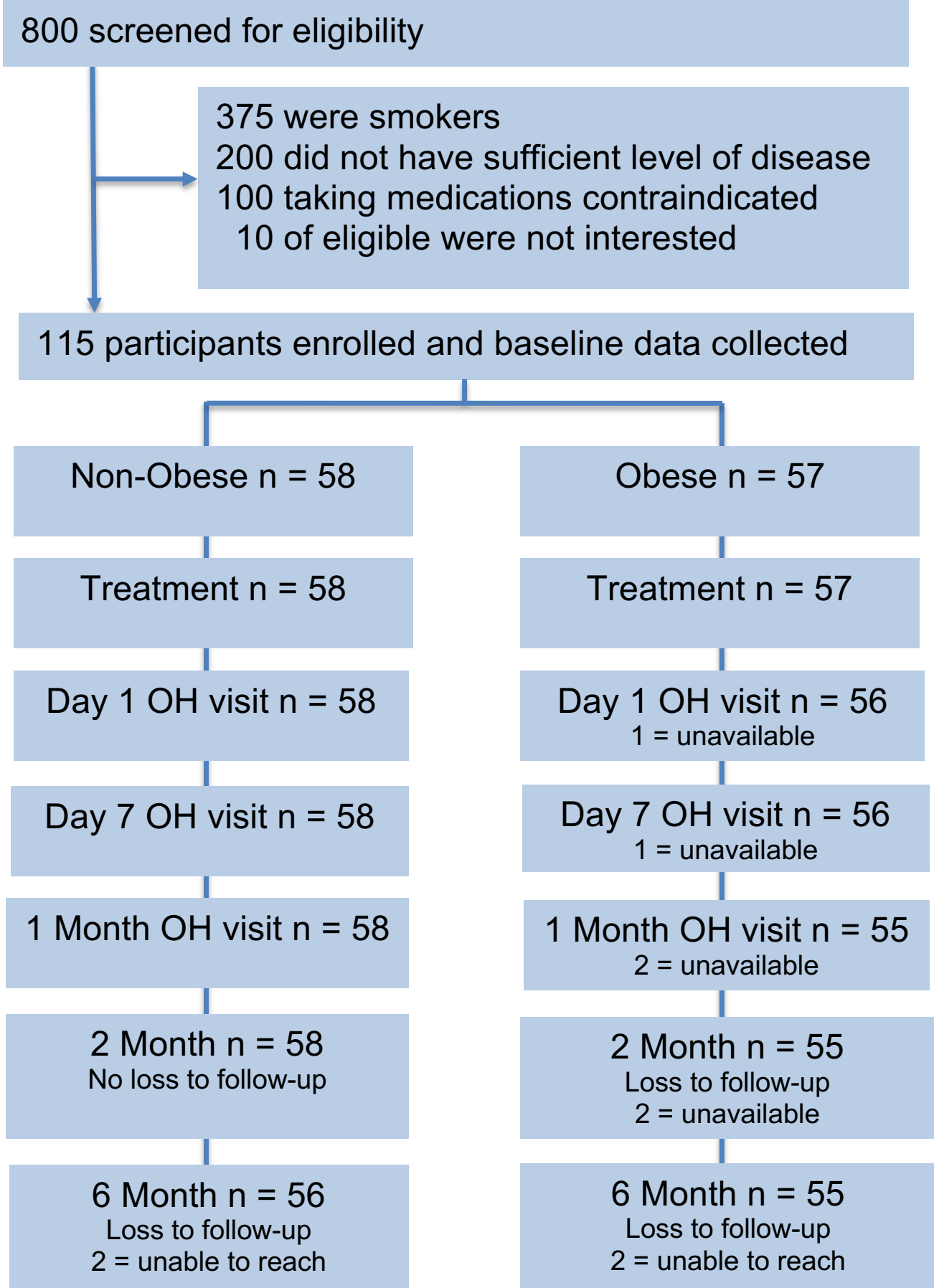

